\title{
Reflets
}

Revue ontaroise d'intervention sociale et communautaire

\section{Coalition contre les rituels de violence faite à la femme}

\section{Mueni Malubungi}

Volume 1, numéro 2, automne 1995

La santé communautaire en Ontario français : défis et espoirs

URI : https://id.erudit.org/iderudit/026088ar

DOI : https://doi.org/10.7202/026088ar

Aller au sommaire du numéro

Éditeur(s)

Reflets : Revue ontaroise d'intervention sociale et communautaire

ISSN

1203-4576 (imprimé)

1712-8498 (numérique)

Découvrir la revue

Citer cet article

Malubungi, M. (1995). Coalition contre les rituels de violence faite à la femme. Reflets, 1(2), 223-227. https://doi.org/10.7202/026088ar

Tous droits réservés (C) Reflets : Revue ontaroise d'intervention sociale et communautaire, 1995
Ce document est protégé par la loi sur le droit d'auteur. L'utilisation des services d'Érudit (y compris la reproduction) est assujettie à sa politique d'utilisation que vous pouvez consulter en ligne.

https://apropos.erudit.org/fr/usagers/politique-dutilisation/ 


\section{Coalition contre les rituels de violence faite à la femme}

\section{M ueni $M$ alubungi}

M embre de la C oalition contre les rituels de violence faite à la femme, Toronto

Toutes les cultures du monde ont pratiqué certaines mutilations sur le corps de la femme. L'imposition des divers rituels de féminité tels que l'excision, l'épilation, l'infibulation, l'allongement du clitoris, qu'il s'agisse des pieds des $\mathrm{C}$ hinoises réduits à des moignons, du génocide de millions de sorcières en Europe du $X I V{ }^{e}$ au XVIe siècle, de la privation ou de la claustration imposée de la puberté jusqu'à la ménaupose dans de nombreux pays d'O rient... O n ignore trop souvent qu'en Europe comme en Amérique, nos belles sociétés civilisées ont pensé elles aussi à rectifier le sexe féminin pour la tranquilité des pères, des maris. Sous prétexte de masturbation, de nymphomanie, d'hystérie ou de folie, des médecins ont eu recours au XIX ${ }^{e}$ et au $X X{ }^{e}$ siècles à l'excision ou à la cautérisation du clitoris (G roulx, 1979).

$\mathrm{LaC}$ oalition contre les rituels de violence faite à la femme est un regroupement de certains organismes francophones qui, depuis deux ans, collaborent à ce dossier suite aux plaintes desfemmes qui avaient subi des pratiques rituellesici ou dans leur pays d'origine. D evant cette urgence, ils ont joint leurs forces pour organiser, grâce à une subvention de ministère de la Santé, une journée de sensibilisation réunissant, le 12 mars dernier, une quarantaine de professionnelles et professionnels de la santé et de l'éducation de $I^{\prime} 0$ ntario français. Suite à leurs recommandations, une coalition francophone sur la prévention des rituels de violence contre la femme a été créée, avec la mission de coordonner l'action à prendre en français, d'éduquer et de sensibiliser, de représenter 
les femmes francophones victimes de toutes sortes de rituels de féminisation, d'établir un consensus et une procédure d'intervention commune auprès de ces femmes, de reconnaître ces rituels de féminité comme agression sexuelle, d'unifier des forces pour amener la compréhension et la sensibilité culturelle, de développer des appuis et des soutiens pour ces femmes afin de les aider à préserver leur intégrité physique et psychologique ainsi que leur dignité humaine. R egroupant des intervenantes elles-mêmes victimes de ces pratiques, la C oalition représente les Francophones auprès des ministères et de la communauté des femmes francophones, regroupées ou non, qui ont subi ou qui luttent contre ce genre d'agression et d'abus. La Coalition a développé d'autres réseaux avec d'autres regroupements de femmes en dehors de I'O ntario comme le $C$ entre desfemmes de $M$ ontréal, le R egroupement des $C$ entres de santé des femmes à $M$ ontréal et le $G$ roupe pour l'abolition des mutilations sexuelles, qui se distingue par l'action qu'il mène en France.

Pour ne pas créer une certaine dispersion dans ses activités, la C oalition procède par dossiers. En effet, sans pour autant ignorer les autres rituels de féminité que subissent les femmes, le groupe concentre son champ d'activité sur les mutilations génitales pratiquées illégalement àToronto et leurs répercussions sur la santé des femmes et des filles. Le cheminement dans ce domaine a permis à la C oalition de constater la totale méconnaissance de ce problème et l'urgence de la situation. II serait aberrant de croire que les mutilations sexuelles tendent à disparaître, car les traditions des pays qui les pratiquent sont très fortes et enracinées. II serait faux de croire que ces pratiques sont restées derrière, qu'elles n'ont pas traversé les frontières. Elles sont là même si aucun cas n'a été rapporté officiellement. Pourquoi le C anada serait-il épargné? La référence aux traditions est très forte. II est également inexact d'associer ces pratiques avec le manque d'éducation moderne ou avec la religion. $C^{\prime}$ 'est la raison pour laquelle la $\mathrm{C}$ oalition cherche à faire de la sensibilisation auprès des professionnels de la santé, de la police, des sociétés d'aide à l'enfance, descentres d'immigration, des travailleuses et travailleurs sociaux, des écoles et des organismes communautaires. 
Il est important de savoir que l'excision est une pratique reliée au rituel de passage: faire passer l'individu d'une situation déterminée à une autre toute aussi déterminée. $\mathrm{N}$ ous pensons que cette pratique, considérée comme une initiation, «concerne à la fois la vie de l'individu et celle de la communauté danslaquelle il vit et avec laquelle il est ou doit être en harmonie, de même qu'avec la nature» (Van Gennep, 1969). Pour D urkheim (1889), I'initiation assure le contrôle de la société organisée et la perpétuation des valeurs éthiques d'une génération à une autre. Pour d'autres anthropologues, elle constitue une éducation morale (l'apprentissage du courage, de l'endurance à supporter les sévices, l'autodiscipline). Eliade, dans Initiation, rites, sodétés secrètes écrit:

"C 'est l'initiation qui confère aux hommes leur statut
humain; avant l'initiation on ne participe pas encore
pleinement à la condition humaine, justement parce
qu'on n'a pas encore accès à la vie religieuse. A ussi
l'initiation constitue t-elle une expérience décisive dans
la vie de tout individu appartenant aux sociétés pré-
modernes: c' est une expérience existentielle fondamen-
tale puisque grâce à elle, I'homme devient capable
d'assumer pleinement son mode d'être» (E liade,
1959:27).

II est intéressant de connaitre les différentes hypothèses présentées par Bettelheim :

- les rites d'initiation, y compris la circoncision, devraient être étudiés dans le contexte des rites de la fertilité;

- les rites d'initiation, à la fois des garçons et des filles, serviraient à promouvoir et à symboliser une pleine acceptation du rôle sexuel que prescrit la société;

- la circoncision pour rait être une tentative de prouver la maturité sexuelle, ou être une mutilation instituée par les femmes, ou encore les deux à la fois;

- la circoncision féminine pourrait résulter en partie de l'ambivalence des hommes à l'égard des fonctions sexuelles féminines et être, en partie, une réaction à la circoncision (Bettleheim, 1971:52-53). 
Prises dans leur ensemble, ces remarques ouvrent la voie à des tentatives de conclusion au sujet des raisons de la persistance actuelle de ces pratiques. En effet, toutes les sociétés et toutes les cultures possèdent et pratiquent des rituels de féminité/ de masculinité sous quelque degré et sous quelque forme que ce soit. II faut reconnaître que certaines cultures ont conservé et pratiquent encore d'une manière plus développée certains types d'initiation. II semble que ce soit dans des cultures de l'oralité que les rites d'initiation sont vécus comme des événements significatifs qui viennent ponctuer les moments forts de la vie sociale et culturelle. B eaucoup d'auteurs ont souligné cet aspect important de l'initiation. D 'ailleurs, c'est ce qu'avancent tous ceux qui préconisent les pratiques mutilatoires.

$M$ ais ces gens oublient que ces interventions génitales constituent une forme de torture et coûtent la vie à des milliers de jeunes filles et de femmes. $0 \mathrm{n}$ ne peut pas continuer à mutiler des êtres humains pour des considérations culturelles. L'excision des organes génitaux des femmes cause des dommages à la santé physique et mentale de celles-ci. Souvent, cette pratique rituelle entraîne de l'hémorragie, de la septicémie, des dommages occasionnés aux organes voisins, gang rène, tétanos, empoisonnement du sang et toute une série d'infections résultant de conditions insalubres et de l'emploi d'outils sales.

À cette pratique s'ajoute l'infibulation. C'est la forme la plus sévère de ces rituels de féminité. Elle va jusqu'à l'ablation de la partie interne des grandes lèvres et à la suture de la vulve, ne laissant qu'une très petite ouverture pour l'écoulement de l'urine et du sang menstruel. Pour «fermer», on se sert d'épines ou on fait une suture avec du catgut : les deux grandes lèvres, râpées à vif, sont maintenues ensemble jusqu'à la cicatrisation. C'est la pratique traditionnelle la plus radicale. $D$ ans certaines cultures, I'infibulation est obligatoire, ce qui garantit visiblement la virginité. L'honneur de la famille est en jeu; plus l'orifice est petit, plusle prix de la mariée est élevé. C esfillesjouissent d'une bonne réputation. L'infibulation se fait sur des petites filles en bas âge, mais dans certaines sociétés, on effectue d'abord l'infibulation avant la puberté et l'excision quand la fille a 12-14 ans ou avant 
les premières menstruations. Les conséquences sont énormes: difficultés d'écoulement du sang menstruel, infections génitales entraînant l'infécondité, problèmes graves lors d'accouchement, chocs psychologiques, etc.

Compte tenu de toutes ces répercussions néfastes sur la santé de la femme et sur son équilibre mental et physique, la C oalition ne cherche à aucun moment à se subsituer aux groupes cibles ni à juger une culture par rapport à l'autre. C 'est un regroupement de femmes ayant subi à un moment dans leur vie d'autres formes de mutilation. N ous voulons agir, notre action va de la prévention à l'intervention. $N$ ous voulons ensemble, malgré nos différences, trouver des stratégies efficaces afin de protéger la vie des femmes et des enfants, quelle que soit leur culture, leur religion, leur race, leur orientation sexuelle. $\mathrm{N}$ ous voulons former une alliance entre les points de vue moderne et traditionnel afin de trouver des solutions à partir de nos pratiques rituelles traditionnelles, tout en nous appuyant sur la solidarité internationale avec les autres femmes.

\section{Bibliographie}

BETTELHEIM , B. (1971). Les blessures symboliques, Paris, Gallimard.

DU R K HEIM , E. (1889). R eprésentation individuelle et représentation collective, Paris.

ELIADE, M. (1959). Initiation, rites, sociétés secrètes, Paris, Gallimard.

GRO U LT, B. (1979). «Les mutilations sexuelles», M agazine, no 14, 50-59.

VAN GEN N EP,A . (1969). R ites de passage, Paris, M outon \& $C 0$ et M aison des Sciences de l'homme

( $T$ itre original : $R$ ites of Passage, 1909). 